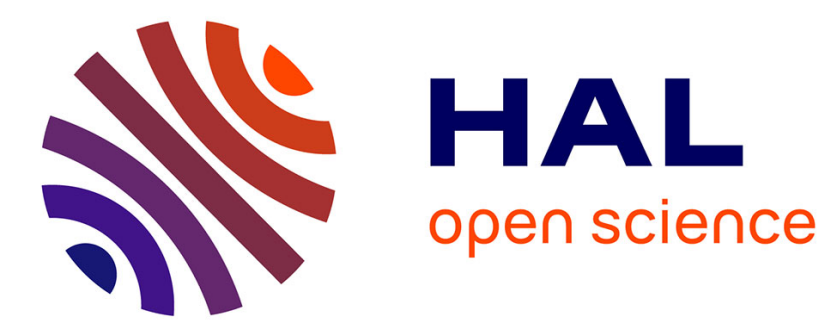

\title{
SPAM (Sex-Structured Pandalus Assessment Model): a stock assessment model for Pandalus stocks
}

\author{
Hilaire Drouineau, L. Savard, M. Desgagnés, D. Duplisea
}

\section{To cite this version:}

Hilaire Drouineau, L. Savard, M. Desgagnés, D. Duplisea. SPAM (Sex-Structured Pandalus Assessment Model): a stock assessment model for Pandalus stocks. Canadian Journal of Fisheries and Aquatic Sciences, 2012, 69 (4), p. 770 - p. 783. 10.1139/F2012-011 . hal-00819260

\section{HAL Id: hal-00819260 \\ https://hal.science/hal-00819260}

Submitted on 30 Apr 2013

HAL is a multi-disciplinary open access archive for the deposit and dissemination of scientific research documents, whether they are published or not. The documents may come from teaching and research institutions in France or abroad, or from public or private research centers.
L'archive ouverte pluridisciplinaire HAL, est destinée au dépôt et à la diffusion de documents scientifiques de niveau recherche, publiés ou non, émanant des établissements d'enseignement et de recherche français ou étrangers, des laboratoires publics ou privés. 


\section{SPAM (Sex-structured Pandalus Assessment Model): a stock} assessment model for Pandalus stocks

- Hilaire Drouineau (corresponding author) ${ }^{1}$

4 Pêches et Océans Canada, Institut Maurice-Lamontagne - 850 route de la Mer - C.P.1000

- Mont-Joli QCG5H3Z4 - CANADA.

hilaire.drouineau@ cemagref.fr

$7 \quad$ Tel : +33(0)5 57892709 fax : +33(0)5 57890801

- Louise Savard

9 Pêches et Océans Canada, Institut Maurice-Lamontagne - 850 route de la Mer - C.P.1000

10 - Mont-Joli QCG5H3Z4 - CANADA

$11 \quad$ Louise.Savard@dfo-mpo.gc.ca

12 - Mathieu Desgagnés

13 Pêches et Océans Canada, Institut Maurice-Lamontagne - 850 route de la Mer - C.P.1000

14 - Mont-Joli QCG5H3Z4 - CANADA

$15 \quad$ Mathieu.Desgagnes@dfo-mpo.gc.ca

16 - Daniel Duplisea

17 Pêches et Océans Canada, Institut Maurice-Lamontagne - 850 route de la Mer - C.P.1000

18 - Mont-Joli QCG5H3Z4 - CANADA

19 Daniel.Duplisea@dfo-mpo.gc.ca

20 Keywords: Pandalus, stock assessment, age-length structured model, hermaphrodism, Pandalus

21 borealis, Sept-Îles

\footnotetext{
${ }^{1}$ New address and affiliation : Cemagref / EPBX unit - 50, avenue de Verdun - 33612
} CESTAS Cedex - FRANCE - hilaire.drouineau@ @emagref.fr - Tel : +33 (0)5 57892709 - fax : +33(0)557890801 
Author-produced version of the article published in Canadian Journal of Fisheries and Aquatic Sciences, 2012, 69(4), 770-783 The original publication is available at http://www.nrcresearchpress.com/toc/cjfas/69/4

doi : 10.1139/f2012-011

\section{Abstract}

23 Despite the economic importance of Pandalus shrimp fisheries, few analytical tools have been

24 developed to assess their stocks and traditional stock assessment models are not appropriate

25 because of biological specificities of Pandalus species. In this context, we propose SPAM, a

26 model dedicated to protandric hermaphrodite Pandalids stock assessment. Pandalids are difficult

27 to assess because the cues affecting sex-change, size at recruitment and mortality variability are

28 not well understood or characterized. The novel structure of the model makes it possible to

29 adequately describe variability in natural mortality by stage and in time, as well as variability in

30 size at sex-change and recruitment. The model provides traditional stock assessment outputs

31 such as fishing mortality estimates, numbers of individuals, and provides in addition yearly

32 natural mortality estimates. The model is applied to the exploited shrimp stock of Pandalus

33 borealis in Sept-Îles as an illustrative example of the utility of the approach. 
Author-produced version of the article published in Canadian Journal of Fisheries and Aquatic Sciences, 2012, 69(4), 770-783 The original publication is available at $\mathrm{http}: / / \mathrm{www} . \mathrm{nrcresearchpress.com/toc/cjfas/69/4}$

doi : 10.1139/f2012-011

\section{Introduction}

35 Shrimp fisheries are becoming more and more important throughout the world. According to

36 FAO, 3,120,566 t of shrimp were caught in marine waters in 2008, representing about $60 \%$ of the

37 total crustacean production and 3.9\% of the world capture fisheries production (FAO 2009). A

38 Pandalidae, Pandalus borealis, is the second most important exploited shrimp species globally,

39 counting for $12.3 \%$ of the global shrimp catches (FAO 2010).

40 Shrimp of the genus Pandalus are exploited in the North Atlantic and the North Pacific

41 oceans mainly by trawl fisheries on large individuals given that shrimp price is often directly

42 linked to its size. This characteristic of the fisheries becomes important because most species of

43 the genus Pandalus (including $P$. borealis) are protandric hermaphrodites, i.e. they reproduce

44 first as males and then change sex and become females (Bergström 2000; Berkely 1930) (Fig. 1).

45 Sex-change is thus critical for fishery management (Fu et al. 2001) since females are primarily

46 targeted by the fishery because of their size. Despite a large literature investigating the factors

47 which potentially influence the activation of the sex-change process, there is currently no clear

48 consensus. Density-dependence effects (Koeller et al. 2000a), size or age (Koeller et al. 2003;

49 Wieland 2004), environmental factors (Wieland 2004) and evolutionary processes (Charnov and

50 Skuladottir 2000) have been studied but none of them alone is a powerful predictor of the yearly

51 variability observed in sex-change. However, sex-change always occurs within a certain length

52 interval, albeit a relatively large one, and consequently, length appears to be a required basis

53 when modelling sex-change.

54 Individuals of $P$. borealis remain as males for some years. Sex-change occurs in winter

55 and newly transformed females can be identified as primiparous females in the following spring

56 and summer. Primiparous females spawn the following fall. Larvae hatch in spring and 
Author-produced version of the article published in Canadian Journal of Fisheries and Aquatic Sciences, 2012, 69(4), 770-783 The original publication is available at $\mathrm{http}: / / \mathrm{www} . \mathrm{nrcresearchpress.com/toc/cjfas/69/4}$

doi : 10.1139/f2012-011

57 reproductive females that survive breeding are then identified as multiparous females.

58 Multiparous and primiparous females can be distinguished by the presence of sternal spines that

59 start disappearing during summer and are definitively lost little time before their first mating

60 (mating occurs few hours/days before spawning - McCrary 1971).

61 Direct determination of age is not possible for $P$. borealis and age can be approximated by the

62 identification of the first modes in length frequency distributions and by the examination of sex

63 related characteristics (Bergström 2000). Growth of males can be adequately modelled with a

64 von Bertalanffy curve (Bergström 2000); however size at recruitment is variable through time

65 (Hvingel and Savard 1997) probably as a consequence of varying environmental conditions

66 during the larval and juvenile phases (Daoud et al. 2010). Male growth rate decreases for oldest

67 males and consequently the largest male length modes can contain individuals of different ages.

68 Absence of direct hard pieces such as otolith combined with the difficulty to distinguish cohorts

69 for largest males hinders the development of reliable aging techniques. Tagging techniques is

70 often used but this technique is more difficult to apply to shrimps because of frequent moulting,

71 small size of the individuals, and is generally expensive. Primiparous females are considerably

72 larger than males of the same age because moult frequency increases during the sex change

73 period. Growth of females is then slow and modes of primiparous and multiparous in length-

74 frequency samples are often difficult to distinguish.

75 Despite the economic importance of crustacean fisheries, few analytical methods have been

76 developed for crustacean stock assessments (Smith and Addison 2003) and more specifically for

77 shrimp stocks. Age structured models have been applied for some crustacean stocks (ICES

78 2003), including shrimp (ICES 2001), but in most cases they were found inappropriate because

79 of the uncertainties in aging techniques and the difficulties to track the cohorts after sex-change. 
Author-produced version of the article published in Canadian Journal of Fisheries and Aquatic Sciences, 2012, 69(4), 770-783 The original publication is available at $\mathrm{http}: / / \mathrm{www} . \mathrm{nrcresearchpress.com/toc/cjfas/69/4}$

doi : 10.1139/f2012-011

80 Catch-Survey-Analysis (Cadrin 2000; Cadrin et al. 1999) and surplus production models have

81 also been applied (Cadrin et al. 2004; NAFO/ICES 2008) to carry out shrimp assessments. They

82 have the advantage of being simple and rather robust, requiring few data. However, a major

83 limitation is that they do not provide any information on the demographical, and especially sex

84 stock structure which can be considerably altered by commercial harvesting and is essential for

85 fishery management. Consequently, shrimp stock assessments often consist of a descriptive

86 analysis of various indicators and trends (for example commercial catch rates and/or survey

87 abundance indices) through time, sometimes formalized in a traffic light approach (Koeller et al.

88 2000b).

89 Length (Drouineau et al. 2008; Drouineau et al. 2010) and age-length structured (Fournier et

90 al. 1998; Quinn et al. 1998; Froysa et al. 2002) models have recently raised more and more

91 interest, especially for species such as shrimp, for which growth is poorly known and aging is

92 difficult. Such models would have several advantages for Pandalus stocks. Indeed, this kind of

93 models can be fitted directly to length-structured data, obviating the need of an uncertain and

94 often expensive length to age data conversion. Moreover, a sex and age-length structured model

95 would enable one to model sex-change in a length interval and to provide valuable information

96 on the demographic structure of the stock. A simulation length-based model with explicit sex-

97 change was first proposed by Fu et al. (2001) to quantify the importance of some biological

98 processes, especially growth, sex-change and natural mortality, but the model was dedicated to

99 understanding the sex-change process rather than as an assessment method.

100 This paper presents SPAM, a model dedicated to protandric hermaphrodite Pandalids stock

101 assessment, that incorporates (i) a length based submodel for male, (ii) a constant growth model

102 but time varying size at recruitment, (iii) a time varying length at sex-change relationship 
Author-produced version of the article published in Canadian Journal of Fisheries and Aquatic Sciences, 2012, 69(4), 770-783 The original publication is available at $\mathrm{http}: / / \mathrm{www} . \mathrm{nrcresearchpress.com/toc/cjfas/69/4}$

doi : 10.1139/f2012-011

103 function and (iv) a stage structure (primiparous/multiparous) submodel for females. Contrary to

104 Fu et al. (2001), a simple two stage structure is used for females whereas the male component 105 relies on a length and age structure. The model is then applied to the exploited Pandalus borealis 106 stock of the Gulf of Saint-Lawrence as an illustration showing the relevance of SPAM to assess a 107 commercially harvested shrimp population.

108 Material and methods

109 Population model

110 The model has a seasonal time step (Fig. 1) which is required to properly describe male 111 growth, seasonal biological processes (sex-change, reproduction) and fishing patterns (variability 112 in catchability linked to seasonal migrations). The first season, namely spring, extends from 113 April to May (hatching season). Summer extends from June to August. Fall starts in September 114 and ends in November (spawning). Finally, winter extends from December to April (sex-change 115 and egg incubation period).

116 The population is primarily divided into male and female components. Male component is age

117 (from age 1 to age A) and length (from length class 1 to L) structured. We assume that males are 118 recruited to the population at age 1 at the beginning of spring; they progress from age a to age $119 \mathrm{a}+1$ also at the beginning of spring (Fig. 1). Quantities related to the male component are 120 subscripted with a $m$, quantities related to the primiparous component are subscripted with primi, 121 quantities related to the multiparous component are subscripted with a multi and quantities 122 related to the female component (both primiparous and multiparous females) are subscripted 123 with a $f e$.

124 The number of males for a given time step $t$, a given age $a$ and a given length class $l$ 
Author-produced version of the article published in Canadian Journal of Fisheries and Aquatic Sciences, 2012, 69(4), 770-783 The original publication is available at http://www.nrcresearchpress.com/toc/cjfas/69/4

doi : 10.1139/f2012-011

125 is $N_{m}(t, a, l)$. The total number of males per time step and length class is denoted by

$126 N_{m}(t, ., l)=\sum_{a} N_{m}(t, a, l)$, while the total number of males per time step and age is

$127 N_{m}(t, a,)=.\sum_{l} N_{m}(t, a, l)$. Male can change sex at different length and age following a sex-change

128 at length transition ogive.

129 Females are subdivided into primiparous and multiparous maturity stages (Fig. 1). Although

130 length-frequency data are also available for females, we consider a two stage structure instead of

131 an age structure because female growth is slow and modes are often confounded. All females go

132 through the primiparous stage before reaching the multiparous stage.

$133 N_{\text {primi }}(t)$ and $N_{\text {multi }}(t)$ stands respectively for the number of primiparous and multiparous

134 females at time step $t$.

135 Assumptions regarding length-at-age

136 Male growth is assumed to follow a von-Bertalanffy growth curve. Consequently, the mean

137 size of the year class $y$ at time step $t$ is:

138

(1) $\mu_{y}(t+1)=\mu_{y}(t)+\left(L_{\infty}-\mu_{y, r}\right) \cdot\left(1-\exp ^{-K \cdot(\Delta t)}\right)$

with $\mu_{y, r}$ the size at recruitment (size at age 1 at the beginning of spring) of the year class and

$\Delta t$ the duration of time step $t$.

$141 L_{\infty}$ is assumed to be known and constant and could be approximated by the maximum length

142 observed for males since growth at age 3 is slow and nearly null at age 4 . Following Fournier et

143 al. (1998) and Maunder and Watters (2003), length distribution of an age group at time step $t$, is

144 assumed to follow a normal distribution with a mean $\mu_{y}(t)$ and a constant coefficient of variation 
$c v$.

147 Quantities related to the sex-change are subscripted with sex. Sex-change is assumed to be

148 length dependent. We assume that the sex-change process is completed at the end of winter

149 before the beginning of the new biological year. The proportion of males that change sex in a 150 given year $y$ is modelled by a sigmoid function of length, characterised by two parameters $L_{50 \text { sex }}(y)$ and $R_{\text {sex }}$ (interquartile range). $L_{50 \text { sex }}(y)$ is assumed to follow a lognormal random walk to account for inter-annual variability in sex-change:

(2) $L_{50 \text { sex }}(y)=L_{50_{\text {sex }}}(y-1) \cdot e^{\varepsilon_{\text {sex }}(y)}$ with $\varepsilon_{\text {sex }}(y) \sim N\left(0, \sigma_{\text {sex }}^{2}\right)$

$$
\text { (3) } p(y, l)=\frac{1}{1+\exp \left(-2 \frac{\log (3)}{R_{\text {sex }}} \cdot\left(l-L_{50 \text { sex }}(y)\right)\right)}
$$

156 However, all males of last age A are forced to change sex.

157 It is necessary to make an assumption about sex-change during final year $\mathrm{Y}$ to provide 158 abundance estimates in year $\mathrm{Y}+1$. Since sex-change is assumed to follow a random walk, it is 159 logical to assume that the sex-change ogive in year $\mathrm{Y}$ is similar to year $\mathrm{Y}-1$.

\section{Survival equations}

161 Survival $S r$ is the result of the natural and fishing mortality. Mean natural mortality $M$ is

162 assumed to be constant over age groups and stages, and is equal at 0.5 year $^{-1}$. Yearly deviations 163 are allowed to account for inter-annual variability: 
(4) $M(y)=M \cdot e^{\varepsilon_{M}(y)}$ with $\varepsilon_{M}(y) \sim N\left(0, \sigma_{M}{ }^{2}\right)$

$M(y)$ denoting the natural mortality in year $y$. section. Survival is computed with the following equations:

169

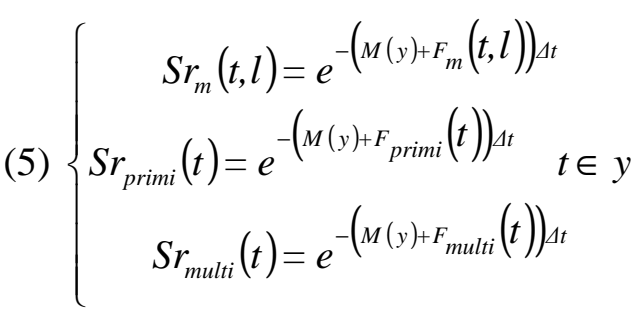

\section{Fishing activity and survey models}

\section{Fishing mortality and catches}

173 Quantities related to the commercial fishery are subscripted with a $f$. Male fishing mortality is

174 assumed to be the product of a selectivity $s_{f}(l)$, a fishing effort $E(t)$ and a year effect $q(y)$ which

175 corresponds to a catchability. Selectivity $s_{f}(l)$ is modelled as a traditional sigmoid function,

176 characterised by two parameters $L_{50 f}$ and $R_{f}$ (interquartile range):

$$
\text { (6) } s_{f}(l)=\frac{1}{1+\exp \left(-2 \frac{\log (3)}{R_{f}} \cdot\left(l-L_{50_{f}}\right)\right)}
$$

178 Male fishing mortality is equal to:

(7) $F_{m}(t, a, l)=q(y) \cdot s_{f}(l) \cdot E(t)$

180 Concerning females, it is assumed that selectivity is equal to 1 given that the newly 181 transformed females reach the sizes that are usually fully recruited to the fishing gear (Shumway 
et al. 1985). Therefore, primiparous females fishing mortality is equal to:

(8) $F_{\text {primi }}(t)=q(y) \cdot E(t)$

184 Females that bear eggs might have, in certain areas, a more specific behaviour than males or 185 primiparous females. In winter and spring, egg bearing females (named multiparous in the model) aggregate inshore, and consequently have a higher catchability (Shumway et al. 1985). A targeting factor $T_{\text {spring,multi }}$ is thus introduced into the calculation of multiparous females fishing mortality in spring to describe this interaction:

$$
\text { (9) } F_{\text {multi }}(t)=\left\{\begin{array}{c}
q(y) \cdot T_{\text {spring,multi }} \cdot E(t) \text { in spring } \\
q(y) \cdot E(t) \text { the rest of the year }
\end{array}\right\}
$$

Year effect is assumed to follow a random walk to avoid unrealistic inter-annual variations:

$$
\text { with } \varepsilon_{f}(y) \sim N\left(0, \sigma_{f}^{2}\right)
$$

192 Given the population numbers and the fishing mortality, expected catches are calculated using traditional Baranov equations:

$$
\text { (11) }\left\{\begin{array}{c}
C_{m}(t, l)=N_{m}(t, ., l) \cdot \frac{F_{m}(t, l)}{M+F_{m}(t, l)} \cdot\left(1-\exp \left(-\left(M+F_{m}(t, l)\right) \cdot \Delta t\right)\right) \\
C_{m}(t)=\sum_{l} C_{m}(t, l) \\
C_{\text {primi }}(t)=N_{\text {primi }}(t) \cdot \frac{F_{\text {primi }}(t)}{M+F_{\text {primi }}(t)} \cdot\left(1-\exp \left(-\left(M+F_{\text {primi }}(t)\right) \cdot \Delta t\right)\right) \\
C_{\text {multi }}(t)=N_{\text {multi }}(t) \cdot \frac{F_{\text {multi }}(t)}{M+F_{\text {multi }}(t)} \cdot\left(1-\exp \left(-\left(M+F_{\text {multi }}(t)\right) \cdot \Delta t\right)\right)
\end{array}\right.
$$

195 Harvest rates $H$ are computed as a ratio of catches in year $y$ over the abundance of the stock at 196 the beginning of that year, i.e. at the beginning of spring, the first seasonal step of a year: 


$$
\left\{\begin{array}{c}
H_{m}(y)=\frac{\sum_{t \in y} \sum_{a} \sum_{l} C_{m}(t, a, l)}{\sum_{a} \sum_{l} N_{m}\left(t_{1}, a l, l\right)} \\
\sum_{\text {primi }}(y)=\frac{\sum_{t \in y} C_{\text {primi }}(t)}{N_{\text {primi }}\left(t_{1}\right)} \\
H_{\text {multi }}(y)=\frac{\sum_{t \in y} C_{\text {multi }}(t)}{N_{\text {multi }}\left(t_{1}\right)}
\end{array}\right.
$$

199 Quantities related to the survey are subscripted with an $s$. Survey abundance indices are

200 assumed to be a relative measure of the stock abundance. Abundance indices are the product of a 201 selectivity $\mathrm{s}_{\mathrm{s}}(l)$, a catchability $q_{s}$ and numbers of shrimp. We use a sigmoid function, 202 characterised by two parameters $L_{50_{s}}$ and $R_{s}$ (interquartile range), to model selectivity for 203 males. Therefore, $s_{s}(l)$ is given by

$$
\text { (13) } s_{s}(l)=\frac{1}{1+\exp \left(-2 \frac{\log (3)}{R_{s}} \cdot\left(l-L_{50_{s}}\right)\right)}
$$

205 Selectivity is assumed to be equal to 1 for the females which are large enough to be totally 206 recruited to the survey trawl. Abundance indices of primiparous and multiparous females 207 estimated by the model are summed into a single female abundance index $I A_{f}$ to be consistent 208 with surveys that are often conducted in fall when the distinction between the two stages of 209 females is difficult or impossible. Given these assumptions, expected abundance indices are 210 given by:

$$
\text { (14) }\left\{\begin{array}{c}
I A_{m}(t, l)=s_{s}(l) \cdot q_{s} \cdot N_{m}(t, ., l) \\
I A_{f e}=q_{s} \cdot\left(N_{p r i m i}(t)+N_{\text {multi }}(t)\right)
\end{array}\right.
$$




\section{Observation model and likelihood function}

213 The model is fitted by maximising a likelihood function which is derived from an observation

214 model that describes the uncertainties around observed data.

\section{Contribution of length-frequency data}

216 Length-frequency samples are available from both commercial and survey catches. A sample

217 consists of the frequencies of males in each length class. Following Fournier et al. $(1990,1998)$

218 and Drouineau et al. (2010), a robust likelihood is used to account for the samples. Basically, it

219 is based on the property that a proportion in a sample follows a normal distribution, and the

220 likelihood is modified to limit the influence of high and low frequencies. The length-likelihood 221 of a sample samp is:

222

$$
\begin{gathered}
\log L(\operatorname{samp}(t) \mid \theta)=\sum_{l}-\frac{1}{2} \cdot \log \left(v_{\text {samp }}(t, l)\right)+\log \left(e^{-\frac{1}{2} \cdot \frac{\left(f(t, l)-f_{\text {obs }}(l)\right)^{2}}{v_{\text {samp }}(t, l)}}+10^{-6}\right) \\
\text { with } v_{\text {samp }}(t, l)=\left((1-f(t, l)) \cdot f(t, l)+\frac{0.1}{L+2}\right) \cdot \frac{1}{n_{\text {samp }}(t)}
\end{gathered}
$$

223 where $n_{\text {samp }}(t)$ is the number of sampled shrimps and $f(t, l)=C_{m}(t, l) / \sum_{i=1}^{L} C_{m}(t, l)$ and

$224 f(t, l)=I A_{m}(t, l) / \sum_{i=1}^{L} I A_{m}(t, l)$ are the expected frequency of length class $l$ estimated by the model

225 for a sample from the commercial fishery and from the scientific survey respectively, and $f_{\text {obs }}(l)$

226 the observed frequency in the sample. 
228 Total commercial catches per time step $\left(C_{m}(t), C_{\text {primi }}(t), C_{m u l t i}(t)\right)$ and total survey abundance

229 indices per time step $\left(I A_{m}(t, l), I A_{f e}(t)\right)$ are assumed to follow a gamma distribution. The gamma

230 distribution is a distribution function that is increasingly used in population dynamic models

231 because of its great flexibility (Froysa et al. 2002; Haddon 2001).

232 The loglikelihood is given by:

233

$\log L C(t \mid \theta)=v_{\text {com }}\left[\log \left(\frac{C_{m, o b s}(t)}{C_{m}(t)}\right)-\frac{C_{m, o b s}(t)}{C_{m}(t)}+\log \left(\frac{C_{\text {primiobs }}(t)}{C_{\text {primi }}(t)}\right)-\frac{C_{\text {primi,obs }}(t)}{C_{\text {primi }}(t)}+\log \left(\frac{C_{\text {multiobs }}(t)}{C_{\text {multi }}(t)}\right)-\frac{C_{\text {multiobs }}(t)}{C_{\text {multi }}(t)}\right]$

236 and

(17) $\log L I A(t \mid \theta)=v_{\text {surv }}\left[\log \left(\frac{I A_{m, o b s}(t)}{I A_{m}(t)}\right)-\frac{I A_{m, o b s}(t)}{I A_{m}(t)}+\log \left(\frac{I A_{f e, o b s}(t)}{I A_{f e}(t)}\right)-\frac{I A_{f e, o b s}(t)}{I A_{f e}(t)}\right]$

$v_{\text {com }}$ and $v_{\text {surv }}$ equal to the inverse of the square root of the coefficient of variation of the

distributions (McCullagh and Nelder 1989).

\section{Parameter estimation}

241 A large number of parameters have to be estimated (Tab. 1). The search domain dimensions

242 quickly increase with the number of years and age groups. Therefore, following Punt (2003),

243 estimation of unknown parameters $\theta$ is split into two steps, growth

244 parameters $\theta_{1}=\left\{K, c v, \mu_{1, r}, \mathrm{~L}, \mu_{Y, r}, \mu_{2}\left(t_{0}\right) \mathrm{L}, \mu_{A}\left(t_{0}\right)\right\}$ being estimated before the remaining

245 parameters $\theta_{2}$ (where $\mathrm{Y}$ denotes the number of years in the data set, ranging from $y_{0}$ to $y_{Y-1}$ ). 
247 The following procedure is used to estimate the loglikelihood $\log L_{2}\left(\theta_{1}\right)$ :

248 1. given $\theta_{l}$, mean size at age $\mu_{a}(t)$ is computed for each age group and each time step (equation 1).

2. given $\theta_{1}$ and given the assumptions regarding the length distribution of an age group, theoretical frequency per length class and per age group is computed.

3. The loglikelihood of a length-frequency sample from commercial or survey catches is computed by a modal analysis with the mean size and standard deviation of the modes kept fixed:

(18) $\log L_{2} P_{\text {samp }}\left(t \mid \theta_{1}\right)=\sum_{l=1}^{L}\left[f(t, l) \cdot \log \left[\sum_{a=1}^{A} \lambda_{\text {samp }}(t, a) \frac{1}{2 \cdot c v \cdot \mu_{a}(t)} \exp \left(-\frac{1}{2}\left(\frac{\operatorname{length}(l)-\mu_{a}(t)}{c v \cdot \mu_{a}(t)}\right)^{2}\right)\right]\right]$

4. Repeat steps 1-3 to $\theta_{1}$ that maximises

(19) $\log L_{2}\left(\theta_{1}\right)=\sum_{t}\left(\log L_{2} P_{\text {samp }}\left(t \mid \theta_{1}\right)\right)$

\section{Estimating other parameters}

260 Given $\theta_{1}$, other parameters are estimated by maximising the loglikelihood which is a function

261 of 5 components: (i) the length composition of commercial and survey catches (equation 15), (ii)

262 the total commercial catches (equation 16), (iii) the total abundance from survey (equation 17),

263 (iv) assumption regarding the random walk of $L 50_{\text {sex }}$ and (v) assumption regarding the random

264 walk of the year effect $q_{f}$ : 


$$
\begin{aligned}
\log L\left(\theta_{2} \mid \theta_{1}\right)=\sum_{t} \log L\left(\operatorname{samp}_{\text {com }}(t) \mid \theta\right) & +\sum_{t} \log L\left(\operatorname{samp}_{\text {surv }}(t) \mid \theta\right)+\sum_{t} \log L C(t \mid \theta)+\sum_{t} \log L I A(t \mid \theta) \\
& +\log _{\text {sex }}(\theta)+\log L_{M}(\theta)+\log L_{f}(\theta)
\end{aligned}
$$

with:

266

(21) $\log L_{s e x}(\theta)=-\frac{1}{2 \cdot \sigma_{s e x}^{2}} \sum_{y} \varepsilon_{s e x}^{2}$

(22) $\log L_{M}(\theta)=-\frac{1}{2 \cdot \sigma_{M}^{2}} \sum_{y} \varepsilon_{M}^{2}$

and:

269

(23) $\log L_{f}(\theta)=-\frac{1}{2 \cdot \sigma_{f}^{2}} \sum_{y} \varepsilon_{f}^{2}$

Following Drouineau et al. (2010), the loglikelihood is maximised using an evolutionary algorithm (Schwefel 1995) that provides a starting point to a quasi-Newton algorithm provided

272 in the autodif library (http://www.otter-rsch.com/). The evolutionary algorithm is a stochastic

273 algorithm which is relevant to explore highly dimensional objective functions and which does

274 not require a starting point to be specified unlike traditional quasi-Newton algorithms. The

275 Hessian matrix is estimated by a finite difference approximation and inverted to get the variance covariance and correlation matrices.

\section{Case study: Gulf of St. Lawrence Pandalus borealis stock}

\section{Description of the fishery}

279 The northern shrimp (Pandalus borealis) fishery began in the Gulf of St. Lawrence (Fig. 2) in 280 the 1960s. The exploitation is conducted by trawlers in four shrimp fishing areas (SFA) (DFO 281 2009). In 2008, the Gulf landings reached about 36,000 tons. The Sept-Îles area (SFA 10) is the 
Author-produced version of the article published in Canadian Journal of Fisheries and Aquatic Sciences, 2012, 69(4), 770-783 The original publication is available at http://www.nrcresearchpress.com/toc/cjfas/69/4

doi : 10.1139/f2012-011

282

most productive of the four stocks representing about $41 \%$ of the total Gulf catch. The fishery is managed by TAC and the number of fishing licenses is regulated. Fishing season starts on April 1 st and closes when the TAC is reached or on the 31 st of December at the latest. There is no fishing in winter mainly because the ice cover prevents access to fishing grounds.

The fishery mainly targets large individuals which are more economically valuable; therefore fishermen allocate a large part of their effort in spring on reproductive females on hatching grounds. On average, females represented $68 \%$ of the Sept-Îles fishing area landings between 1990 and 2008.

Fishers are required to fill out a logbook, indicating the number of hours fished and a dockside monitoring program ensures control over landings. Both log-book and dockside programs have provided very reliable estimates of fishing effort and catches since 1990. The commercial catches are sampled regularly during the fishing season and a bottom trawl survey is conducted each year at the end of summer. The catch sampling program has been running since 1982 and the research survey has been conducted since 1990. The total number of shrimp measured each year varies from 8,000 to 18,000 for the commercial sampling as well as for the survey.

\section{Input data}

Catch at length is available for males by time step (except in winter) and abundance at length is available for males for the second time step (in summer), both from 1990 to 2008 . Cephalothorax lengths are aggregated into $0.5 \mathrm{~mm}$ classes (they are measured at the nearest 0.1 $\mathrm{mm}$ ) and range from 8.0 to $27.0 \mathrm{~mm}$. In the Sept-Îles area, shrimp larvae hatch in early May (Ouellet et al. 2007). In fall the year after, they are $1 \frac{1}{2}$ year old and measure between 8.0 and 
Author-produced version of the article published in Canadian Journal of Fisheries and Aquatic Sciences, 2012, 69(4), 770-783 The original publication is available at $\mathrm{http}: / / \mathrm{www} . \mathrm{nrcresearchpress.com/toc/cjfas/69/4}$

doi : 10.1139/f2012-011

$30412.0 \mathrm{~mm}$. They are between 12.0 and $16.0 \mathrm{~mm}$ at $2 \frac{1}{2} 2$ y.o., 16.0 and $19.0 \mathrm{~mm}$ at $31 \frac{1}{2}$ y.o. and 19.0

305 and 23.0 at $4 \frac{1}{2}$ y.o. The maximum size is $28.0 \mathrm{~mm}$ but few males are found at sizes larger than

$30624 \mathrm{~mm}$. Sex-change occurs after mating (which occurs few hours/day before female spawning),

307 in winter, before they reach the age of 5. Controlled growth experiment studies confirmed this

308 growth pattern (Daoud et al. 2010). Indeed, the authors found that, at $5{ }^{\circ} \mathrm{C}$ which is about the

309 bottom temperature of the area, $20.0 \mathrm{~mm}$ males are 4 years old.

310 Female catch and abundance data are available from 1990 to 2008. Females are split into two

311 stages (primiparous and multiparous females) for the commercial catch for spring and summer.

312 The separation is not done for the fall season and for the survey. In the Sept-Îles area, spawning

313 occurs in early October. Primiparous females spawn 6 months or so after having changed sex.

314 Egg bearing females migrate and aggregate inshore in winter and spring. This behaviour has an

315 impact on their availability to the fishing fleet. Therefore, a targeting factor was introduced to the

316 model to account for this migratory behaviour.

\section{Specific parameters values}

318 Some specific parameters values were fixed for the Sept-Îles case study according to expert

319 knowledge (Tab. 2). We set $v_{\text {com }}=v_{\text {surv }}=100$ which corresponds to a $\mathrm{CV}$ of $10 \%$. We set $320 \sigma_{f}=0.05$ which corresponds to a random walk of coefficient of variation to $5 \%$, given that

321 fishing activity is well known and that catchability is not expected to have changed a lot over the

322 period. Although there is little information on natural mortality inter-annual variability, we

323 choose to fix $\sigma_{M}=0.05$, to have equivalent weights between natural and fishing mortality

324 deviations. In the absence of information over sex-change, we choose to let more flexibility to

325 the sex-change random walk and fix $\sigma_{\text {sex }}=0.10$. 
Author-produced version of the article published in Canadian Journal of Fisheries and Aquatic Sciences, 2012, 69(4), 770-783 The original publication is available at $\mathrm{http}: / / \mathrm{www} . \mathrm{nrcresearchpress.com/toc/cjfas/69/4}$

doi : 10.1139/f2012-011

The model includes 4 male age groups and is fitted over a 19 years data series. Consequently

327111 parameters should be estimated (24 in phase 1 and 87 in phase 2 - Table 1$)$.

\section{Results}

\section{Fitting observed data}

330 The model properly fits length-compositions of the male component with modes that can be easily detected (Fig. 3a, Fig. 3b and Fig. 4), demonstrating the adequacy of the growth model and of the use of a time step.

333 The seasonal pattern of landings was captured as well in the fitting (Fig. 5). Each year, a peak 334 of catches is observed in spring that corresponds to the fishery targeting multiparous females 335 which are aggregated on the hatching grounds. The model poorly fits summer catches for the last 336 two years, probably because the estimates rely on only a few data points. More generally, the fits 337 are a bit poorer for the summer season than for the two other fishing seasons since the late 338 1990's, perhaps indicating a change in fishing behaviour over the period. Globally, catches have 339 increased through time over the period (Fig. 5) as a consequence of an increase in TAC (DFO 340 2009).

341 The global trend in total survey abundance indices estimated by the model is consistent with 342 the observations, except for 2003 (Fig. 6). However, a strong year effect in the survey was 343 detected for many species for that year (DFO 2009). Globally, the model tends to smooth the 344 survey signal, which is not surprising given the random walk employed in the model.

\section{Population numbers}

346 Recruitment at age one (Figs. 7 and 8) estimated by the model is variable with two periods of 
Author-produced version of the article published in Canadian Journal of Fisheries and Aquatic Sciences, 2012, 69(4), 770-783 The original publication is available at $\mathrm{http}: / / \mathrm{www} . \mathrm{nrcresearchpress.com/toc/cjfas/69/4}$

doi : 10.1139/f2012-011

347 higher recruitments in early 90's and then in early 2000's. Those strong year classes are

348 especially prominent at $15 \mathrm{~mm}$ (2 years old) in the length compositions of the 1992, 1999 and

3492001 commercial catches (Fig. 3) and at $10 \mathrm{~mm}$ (1 year old) in the 1991, 1998 and 2000 survey

350 length compositions (Fig. 4). The abundance of females (primiparous and multiparous) also

351 shows the same trend with however a few years lag (Fig. 9a). The abundance of females has

352 been gradually decreasing for the last four to five years probably due to the decreasing

353 abundance of males estimated from 2003 to 2007 . Recruitment seems to be slightly decreasing in

354 latter years, therefore, a decrease in total abundance is expected in the future (the number of

355 males increased in recent year, but it is probably because of a delayed sex-change).

356 No obvious stock-recruitment relationship is observed (Fig. 8). The strong year classes are not

357 explained by a high abundance of females and are more likely due to favourable environmental

358 conditions improving larval survival (Ouellet et al. 2011).

359 Theoretically, the model provides absolute population number estimates, however a rather

360 high correlation is observed between catchability (of both survey and commercial fishery) and

361 recruitment in first year estimates. Consequently, the population number estimates (and therefore

362 the harvest rates) are more likely to be relative abundance estimates.

\section{Natural and fishing mortality rates}

364 The model provides natural and fishing mortality estimates for males and females at each time

365 step (Fig. 9b - male and multiparous female fishing mortality rates are not represented, since they

366 are equal to the primiparous mortality rate multiplied by a constant through time). A high level

367 of both natural and fishing mortality rates at the beginning of the 1990s explains the low

368 abundance of multiparous in the same period. A sudden decrease in natural mortality first, 
Author-produced version of the article published in Canadian Journal of Fisheries and Aquatic Sciences, 2012, 69(4), 770-783 The original publication is available at $\mathrm{http}: / / \mathrm{www} . \mathrm{nrcresearchpress.com/toc/cjfas/69/4}$

doi : 10.1139/f2012-011

369 followed by a more limited decrease in fishing mortality with the combination of high

370 recruitment resulted in a period of relatively high female abundance between 1996 and 2001.

371 Similarly, the second peak of female abundance in the 2000's happened after a period of high

372 recruitment, lower fishing mortality, and decreasing natural mortality which continued to

373 decrease till 2006. The recent decrease in the abundance of females is probably due to both an

374 increase in the natural mortality rate estimated for the last two years, and a substantial increase in

375 fishing mortality since 2003.

376 Year effects do not exhibit strong variations through the period; however a model with a 377 constant year effect was rejected by the Akaike Information Criterion (Akaike 1973).

\section{Sex-change}

379 The model relies on a time-varying sex-change-at-length relationship. A time constant

380 function was tested but rejected by the Akaike Information Criterion, demonstrating that inter-

381 annual variability in sex-change is significant.

382 The two extreme ogives of sex-change-at-length show that in some years, a significant 383 proportion of males may anticipate sex-change and become females before reaching age 4 or 384 even age 3 (Fig. 10). In other years, exclusively males of age 4 change sex. This may explain 385 why the mode corresponding to age 4 is often hardly distinguished from the mode corresponding 386 to age 3 in length-composition samples. It might also explain why the prediction of the 387 abundance of primiparous females from the abundance of males is uncertain though it would be 388 very important for management. Globally, length-at-sex-change has shown great variations in 389 primiparous length (Fig. 10) which have likely induced variations in female length (DFO 2009). 
Author-produced version of the article published in Canadian Journal of Fisheries and Aquatic Sciences, 2012, 69(4), 770-783 The original publication is available at $\mathrm{http}: / / \mathrm{www} . \mathrm{nrcresearchpress.com/toc/cjfas/69/4}$

doi : 10.1139/f2012-011

\section{Discussion and perspectives}

391 This study presents a sex, age and length structured model dedicated to shrimp stock

392 assessment. To our knowledge, it is the first assessment model designed specifically for Pandalid

393 shrimps, a species that changes sex and for whom ageing after the sex-change is difficult, if not

394 impossible. Our model is a sex-structured model with a length-based submodel for males and a

395 simple stage-structured submodel for females. To characterise a Pandalid shrimp fishery,

396 modelling the sex-change process from males to females is critical and this length-stage-sex-

397 structured model should thus be considered as at least a way to take this biological process into

398 account. The age-length structure of the male component is required to properly model sex-

399 change given that the size at sex-change varies over time as indicated by the variations in the size

400 of newly transformed females. A more simple stage-structured submodel is used for females

401 because (i) females growth is slow and it is difficult to distinguish modes in length-frequency

402 samples while the presence/absence of sternal spines provide a more reliable discrimination

403 method between primiparous and multiparous females and (ii) females being fully recruited to

404 the fishing gear, their size compositions are not essential for a stock assessment model. The age

405 structure of females can be approximated by the two stages, primiparous (newly transformed

406 females) and multiparous females which can be distinguished by morphological differences.

407 The model demonstrates a high inter-annual variability in length at sex-change. Consequently,

408 the numbers of newly transformed females are difficult to predict from one year to the next. We

409 totally agree with Fu et al. (2001) when stating that a better understanding of sex-change would

410 be a valuable improvement for Pandalus stocks management, especially for stocks where

411 females are such a large component of the commercial catches. Females represent the spawning

412 population and constitute the main target of the commercial fisheries and thus they need to be 
Author-produced version of the article published in Canadian Journal of Fisheries and Aquatic Sciences, 2012, 69(4), 770-783 The original publication is available at $\mathrm{http}: / / \mathrm{www} . \mathrm{nrcresearchpress.com/toc/cjfas/69/4}$

doi : 10.1139/f2012-011

413 effectively managed to prevent stock depletion. Moreover, the results of the model on the yearly

414 variations in size at sex-change will probably help to investigate the process and find relevant

415 explanatory covariables. More specifically, density-dependant influence on the variations in size

416 at sex-change may be investigated in the future, since we observed that periods of high or

417 increasing levels in males abundance correspond to periods with low size at sex-change.

418 Estimating natural mortality yearly deviations was possible because of the absence of fishing

419 in winter due to ice cover. Natural mortality is then not confounded with fishing mortality during

420 this season. The correlation matrix analysis shows that though year to year natural mortality

421 deviations were slightly correlated, they were not correlated to catchability deviations (year

422 effects), confirming that it was possible to at least partially estimate those deviations. The

423 assumption of yearly deviations around a mean seemed sufficient to catch the main trends in the

424 population numbers. However, shrimp natural mortality is known to be correlated to the

425 abundance of important predators such as cod and redfish, which have decreased substantially in

426 many of the Northwest Atlantic shrimp fishing areas. Consequently, it may prove necessary in

427 the future to describe the predation process in the model to clearly distinguish $F$ and $M$

428 throughout the time series. Moreover, we assumed that $M$ was constant over age and length in

429 the absence of more precise information, more precise mortality-at-length estimates would be a

430 valuable improvement to the model.

431 The model has been used to assess the Sept-Îles shrimp stock as an illustrative example. The

432 model provides results which are consistent with existing knowledge on the species and the stock

433 (DFO 2009).

434 Weights on sex-change (equation $2-\sigma_{\text {sex }}$ ), natural mortality (equation $4-\sigma_{M}$ ) and year

435 effect random walks (equation $10-\sigma_{f}$ ) were fixed rather arbitrarily. However our objective in 
Author-produced version of the article published in Canadian Journal of Fisheries and Aquatic Sciences, 2012, 69(4), 770-783 The original publication is available at http://www.nrcresearchpress.com/toc/cjfas/69/4

doi : 10.1139/f2012-011

436 this paper was to present an illustrative example. In a formal stock assessment context, those

437 weights should be discussed with experts and adapted to each stock, and sensitivity analysis

438 should be carried out. We think that the model is generic enough to be applied to different

439 Pandalus stocks, if reliable data from both scientific survey and commercial fishery are

440 available. Moreover, the model needs reliable fishing effort data to estimate the seasonal pattern

441 in fishing activity.

442 The present model was specifically developed to assess Pandalus shrimp stocks. Traditional

443 models such as stage-structured models (CSA), surplus production models or age-structured

444 models proved to be poorly adapted to such species because of the absence of aging techniques

445 and the non integration of the sex-change process. In SPAM, the age, length and sex structure

446 provides relevant solutions to both problems. However, a rather large amount of data is required

447 to fit the model, which can be justified by the economic importance of the fishery.

448 On the whole, results are consistent with the traditional assessment (DFO 2009) confirming a

449 present high abundance level compared to the early 1990's. However, short or medium term

450 projections are possible with SPAM, and consequently, managers may detect more quickly

451 variations in abundance and adapt management measure (TAC) accordingly. More specifically,

452 the detailed male length-structured abundance estimates and sex change at length ogive are

453 valuable information to managers to anticipate more precisely the number of females in the years

454 to come, which are especially targeted by the commercial fishery.

455 Finally, the model may be used as an operating model in a management strategy evaluation

456 (MSE) framework (Butterworth and Punt 1999; Punt and Donovan 2007; Sainsbury et al. 2000).

457 MSE aims at assessing the robustness of management options regarding various sources of

458 uncertainty. It relies on an operating model that is able to simulate realistic population dynamics 
Author-produced version of the article published in Canadian Journal of Fisheries and Aquatic Sciences, 2012, 69(4), 770-783 The original publication is available at http://www.nrcresearchpress.com/toc/cjfas/69/4

doi : 10.1139/f2012-011

\section{Acknowledgments}

\section{References}

under various scenarios. The model seems to be able to reproduce Pandalid shrimp stock trends and is flexible enough (especially if one adds time varying natural mortality and size at sexchange) to simulate various plausible scenarios of stock evolution.

Akaike H. 1973. Information theory as an extension of the maximum likelihood principle, In 2nd International Symposium on Information Theory. Edited by Petrov B. N. , CsaksiF. (Eds.). Akademiai Kiado, Budapest, Hungary. 267-281.

Bergström B. I. 2000. The biology of Pandalus. Adv. Mar. Biol. 38: 55-245.

Berkely A. A. 1930. The post-embryonic development of the common pandalids of Bristich Columbia. Contrib. Can. Biol. Fish. (NS) 6: 79-163.

Butterworth D. and Punt A. 1999. Experiences in the evaluation and implementation of management procedures. ICES J. Mar. Sci. 56(6): 985-998.

Cadrin S. X. 2000. Evaluating two assessment methods for Gulf of Maine northern shrimp based on simulations. Journal of Northwest Atlantic Fishery Science 27: 119-132.

Cadrin S. X., Boutillier J. A. and Idoine J. S. 2004. A hierarchical approach to determining reference points for Pandalid shrimp. Can. J. Fish. Aquat. Sci. 61(8): 1373-1391. 
Author-produced version of the article published in Canadian Journal of Fisheries and Aquatic Sciences, 2012, 69(4), 770-783 The original publication is available at http://www.nrcresearchpress.com/toc/cjfas/69/4

doi : 10.1139/f2012-011

478 Cadrin S. X., Clark S. H., Schick D. F., Armstrong M. P., McCarron D. and Smith B. 1999.

479 Application of Catch-Survey Models to the Northern Shrimp Fishery in the Gulf of Maine.

480 North American Journal of Fisheries Management 19(2): 551-568.

481 Charnov E. L. and Skuladottir U. 2000. Dimensionless invariants for the optimal size (age) of 482 sex change. Evolutionary Ecology Research 2(8): 1067-1071.

483 Daoud D., Lambert Y., Audet C. and Chabot D. 2010. Size and temperature-dependent variations 484 in intermolt duration and size increment at molt of Northern Shrimp, Pandalus borealis. 485 Marine Biology 157(12): 2655-2666.

DFO 2009. Assessment of shrimp stocks in the Estuary and Gulf of St. Lawrence in 2008. DFO Can. Sci. Advis. Sec., Sci. Advis. Rep. 2009/001.

Drouineau H., Mahévas S., Bertignac M. and Fertin A. 2008. Assessing the impact of discretisation assumptions in a length-structured population growth model. Fisheries Research 91(2-3): 160-167.

Drouineau H., Mahévas S. and Bertignac M. 2010. A length-structured and spatialised model for the Northern stock of European hake (Merluccius merluccius). ICES Journal of Marine Science 67(8): 1697-1709.

FAO 2009. FAO Yearbook. Fishery Statistics 2008, I1013/T, Food and Agriculture Organization of the United Nations. Rome/Roma, FAO. 2010. 72p.

496 Fournier D. A., Hampton J. and Sibert J. R. 1998. MULTIFAN-CL: a length-based, age497 structured model for fisheries stock-assessment, with application to South Pacific albacore, 498 Thunnus alalunga. Can. J. Fish. Aquat. Sci. 55(9): 2105-2116.

499 Fournier D. A., Sibert J. R., Majkowski J. and Hampton H. 1990. MULTIFAN a likelihood- 
500 based method for estimating growth parameters and age composition from multiple length

501 frequency data sets illustrated using data for southern bluefin tuna (Thunnus maccoyii). Can.

503 Froysa K. G., Bogstad B. and Skagen D. W. 2002. Fleksibest- an age-length structured fish stock assessment model. Fisheries Research 55(1-3): 87-101.

505 Fu C., Quinn II T. J. and Shirley T. C. 2001. The role of sex change, growth and mortality in

506 Pandalus population dynamics and management. ICES J. Mar. Sci. 58(3): 607-621.

Haddon M. 2001. Modelling and Quantitative methods in fisheries, second edition. Chapman \& Hall, London.

Hvingel C. and Savard L. 1997. Northern shrimp research in the North Atlantic - state of the art and future research strategy, 1997:592, TemaNord.

511 ICES 2001. Report of the Pandalus assessment working group, ICES CM 2001/ACFM:04, ICES.

512 ICES 2003. Report of the Working Group on Nephrops Stocks, ICES CM 2003/ACFM:18, $513 \quad$ ICES.

514 Koeller P. A., Covey M. and King M. 2003. Is size at sex transition an indicator of growth or 515 abundance in pandalid shrimp? Fisheries Research 65(1-3): 217-230.

516 Koeller P., Mohn R. and Etter M. 2000a. Density dependent sex change in northern shrimp, $517 \quad$ Pandalus borealis, on the Scotian Shelf. Journal of Northwest Atlantic Fishery Science 27: $518 \quad 107-118$

519 Koeller P., Savard L., Parsons D. G. and Fu C. 2000b. A precautionary approach to assessment 520 and management of shrimp stocks in the northwest Atlantic. Journal of Northwest Atlantic 521 fishery science 27: 235-246. 
Author-produced version of the article published in Canadian Journal of Fisheries and Aquatic Sciences, 2012, 69(4), 770-783 The original publication is available at http://www.nrcresearchpress.com/toc/cjfas/69/4

doi : 10.1139/f2012-011

522 Maunder M. N. and Watters G. M. 2003. A-SCALA: un analisis estadistico de captura a talla

523 estructurado por edad para la evaluacion de las poblaciones de atunes en el oceano pacifico

524 oriental. Bulletin Inter-American Tropical Tuna Commission 22(5): 531-581.

McCrary J. A. 1971. Sternal spines as a characteristic for differentiating between females of some pandaleidae. Journal of the Fisheries Research Board of Canada 28: 98-100.

McCullagh P. and Nelder J. A. 1989. Generalized Linear Models. Chapman \& Hall, London.

NAFO/ICES 2008. Report of the NAFO/ICES Pandalus Assessment Group, NAFO SCS Doc. 08/25;ICES CM 2008/ACOM:11, NAFO/ICES.

Ouellet P., Fuentes-Yaco, C., Savard L., Platt, T., Sathyendranath, S., Koeller, P., Orr, D. and Siegstad, H. 2011. Ocean surface characteristics influence recruitment variability of populations of northern shrimp (Pandalus borealis) in the Northwest Atlantic. ICES J. Mar. Sci. 68: 737-744.

Ouellet P., Savard L. and Larouche P. 2007. Spring oceanographic conditions and northern shrimp Pandalus borealis recruitment success in the north-western Gulf of St. Lawrence. Mar. Ecol.: Prog. Ser. 339: 229-241.

Punt A. E. 2003. The performance of a size-structured stock assessment method in face of spatial 538 heterogeneity in growth. Fisheries Research 65(1): 391-409.

539 Punt A. E. and Donovan G. P. 2007. Developing management procedures that are robust to 540 uncertainty: lessons from the International Whaling Commission. ICES J. Mar. Sci 64(4): $541 \quad 603-612$.

542 Quinn T. J., Turnbull C. T. and Fu C. 1998. A length-based model for hard-to-age invertebrate populations. Proc. Symp. Fishery Stock Assess. Models $21^{\text {st }}$ Cent. Alaska Sea Grant College 
Author-produced version of the article published in Canadian Journal of Fisheries and Aquatic Sciences, 2012, 69(4), 770-783 The original publication is available at http://www.nrcresearchpress.com/toc/cjfas/69/4

doi : 10.1139/f2012-011

544 Program, Fairbanks AK: 531-556.

545 Sainsbury K., Punt A. and Smith A. 2000. Design of operational management strategies for

546 achieving fishery ecosystem objectives. ICES J. Mar. Sci. 57(3): 731-741.

547 Schwefel H. P. 1995. Evolution and Optimum Seeking. Wiley \& Sons, New-York.

548 Shumway S. E., Perkins H. C., Shick D. F. and Stickney A. P. 1985. Synopsis of biological data

549 of the pink shrimp, Pandalus borealis, (Krøyer 1838), FAO Fisheries Synopsis No. 44;

550 National Oceanic and Atmospheric Administration Technical report of the National Marine

$551 \quad$ Fisheries Services 30, Seattle, Washington.

552 Smith M. T. and Addison J. T. 2003. Methods for stock assessment of crustacean fisheries.

553 Fisheries Research 65(1-3): 231-256.

554 Wieland K. 2004. Length at sex transition in northern shrimp (Pandalus borealis) off West

555 Greenland in relation to changes in temperature and stock size. Fisheries Research 69(1): 49-

55656. 
Author-produced version of the article published in Canadian Journal of Fisheries and Aquatic Sciences, 2012, 69(4), 770-783 The original publication is available at http://www.nrcresearchpress.com/toc/cjfas/69/4

doi : 10.1139/f2012-011

Table 1. Unknown parameters and their significance ( $\mathrm{Y}$ stands for the number of years in the

559 dataset).

\begin{tabular}{|c|c|c|}
\hline Type of parameters & Parameters & $\begin{array}{l}\text { Number of } \\
\text { parameters }\end{array}$ \\
\hline \multirow[t]{4}{*}{ Growth } & $K$ & 1 \\
\hline & $c v$ & 1 \\
\hline & Mean size at recruitment $\mu_{y, r}$ & $\mathrm{Y}$ \\
\hline & $\begin{array}{l}\text { Mean size of male age groups (but recruitment) } \\
\text { in first time step } \mu_{a}\left(t_{0}\right)\end{array}$ & A-1 \\
\hline Sex-change & $L_{50 s e x}\left(y_{0}\right) R_{\text {sex }} \varepsilon_{\text {sex }}\left(y_{1}\right) \varepsilon_{\text {sex }}\left(y_{2}\right) \ldots \varepsilon_{\text {sex }}\left(y_{Y-2}\right)$ & Y \\
\hline Natural mortality & $\varepsilon_{M}(y)$ & $\mathrm{Y}$ \\
\hline \multirow[t]{2}{*}{ Initial numbers } & First year $N_{m}(1, a,.) N_{\text {primi }}(1) N_{\text {multi }}(1)$ & $A+2$ \\
\hline & Yearly recruitment $N_{m}(y, 1,)$. & $\mathrm{Y}-1$ \\
\hline \multirow{3}{*}{$\begin{array}{l}\text { Commercial } \\
\text { fishery }\end{array}$} & Selectivity $L_{50 f}, R_{f}$ & 2 \\
\hline & Catchability $q\left(y_{0}\right) \varepsilon_{f}\left(y_{1}\right) \varepsilon_{f}\left(y_{2}\right) \ldots \varepsilon_{s f}\left(y_{Y-1}\right)$ & Y \\
\hline & Multiparous targetting $T_{\text {spring,multi }}$ for spring & 1 \\
\hline \multirow[t]{2}{*}{ Survey } & Selectivity $L_{50 s} R_{s}$ & 2 \\
\hline & Catchability $q_{s}$ & 1 \\
\hline
\end{tabular}


Author-produced version of the article published in Canadian Journal of Fisheries and Aquatic Sciences, 2012, 69(4), 770-783 The original publication is available at http://www.nrcresearchpress.com/toc/cjfas/69/4

doi : 10.1139/f2012-011

560 Table 2. Fixed parameters' values for the Sept-Îles case study

\begin{tabular}{|c|c|}
\hline Parameters & Value \\
\hline $\mathrm{A}$ & 4 \\
\hline $\mathrm{L}$ & 38 \\
\hline$y_{0}$ & 1990 \\
\hline $\mathrm{Y}$ & 19 \\
\hline$L_{\infty}$ & 28 \\
\hline$v_{\text {com }}$ & 100 \\
\hline$v_{\text {surv }}$ & 100 \\
\hline$\sigma_{f}$ & 0.05 \\
\hline$\sigma_{M}$ & 0.05 \\
\hline$\sigma_{s e x}$ & 0.1 \\
\hline
\end{tabular}


Author-produced version of the article published in Canadian Journal of Fisheries and Aquatic Sciences, 2012, 69(4), 770-783 The original publication is available at $\mathrm{http}: / / \mathrm{www} . \mathrm{nrcresearchpress.com/toc/cjfas/69/4}$

doi : 10.1139/f2012-011

563 Fig. 1. Illustration of the life cycle of a protandric hermaphrodite Pandalus species and model

564 time-steps (winter, spring, summer autumn) Arrows represent (age or stage or sex) transitions 565 occurring instantaneously between two successive time-steps.

566 Fig. 2. Sept-Îles stock location in the Gulf of Saint-Lawrence.

567 Fig. 3a. Observed (normal lines) and estimated (bold lines) length-composition of male 568 commercial catches per season and per year from 1990 to 1999. Scales on Y axis cannot be 569 compared between seasons and years.

570 Fig. 3b. Observed (normal lines) and estimated (bold lines) length-composition of male 571 commercial catches per season and per year from 2000 to 2008. Scales on Y axis cannot be 572 compared between seasons and years.

573 Fig. 4. Observed (normal lines) and estimated (bold lines) male length-composition of survey 574 catches. Scales on Y axis cannot be compared between years.

575 Fig. 5. Observed (bold solid line and squares) and estimated (solid line and circles) total 576 commercial catches per season (spring: black point, summer: grey point, fall: white point) and 577 year.

578 Fig. 6. Observed (bold line and squares) and estimated (normal line and circles) total survey 579 abundances per year

$580 \quad$ Fig. 7. Estimated recruitment at age 1.

581 Fig. 8. Estimated stock recruitment relationships: females in autumn against males of age 1 582 following spring.

583 Fig. 9. a) Estimated population numbers obtained from the assessment model : numbers for 584 males (ages 2 to 4), primiparous and multiparous females at the beginning of spring, i.e. before 
585 the fishing season and b) estimated natural mortality (dotted line) and spring fishing mortality of

586 primiparous females (multiparous mortality is equal to the primiparous mortality multiplied by

587 the targeting factor - solid line).

588 Fig. 10. Estimated ogive of sex change at length for two extreme years (end of year 1996 and 589 end of year 2007) (left) and evolution of $L 50_{\text {sex }}(y)$ over the period (right). Vertical dashed lines 590 represent the mean sizes at the period of sex change (Fig. 1) of each male group $591 \quad \mu_{a}=\sum_{y=y_{0}}^{y_{Y-1}} \mu_{a}\left(t_{1}\right) / Y\left(\right.$ with $t_{1}$ spring of year $\left.y\right)$ 
Author-produced version of the article published in Canadian Journal of Fisheries and Aquatic Sciences, 2012, 69(4), 770-783

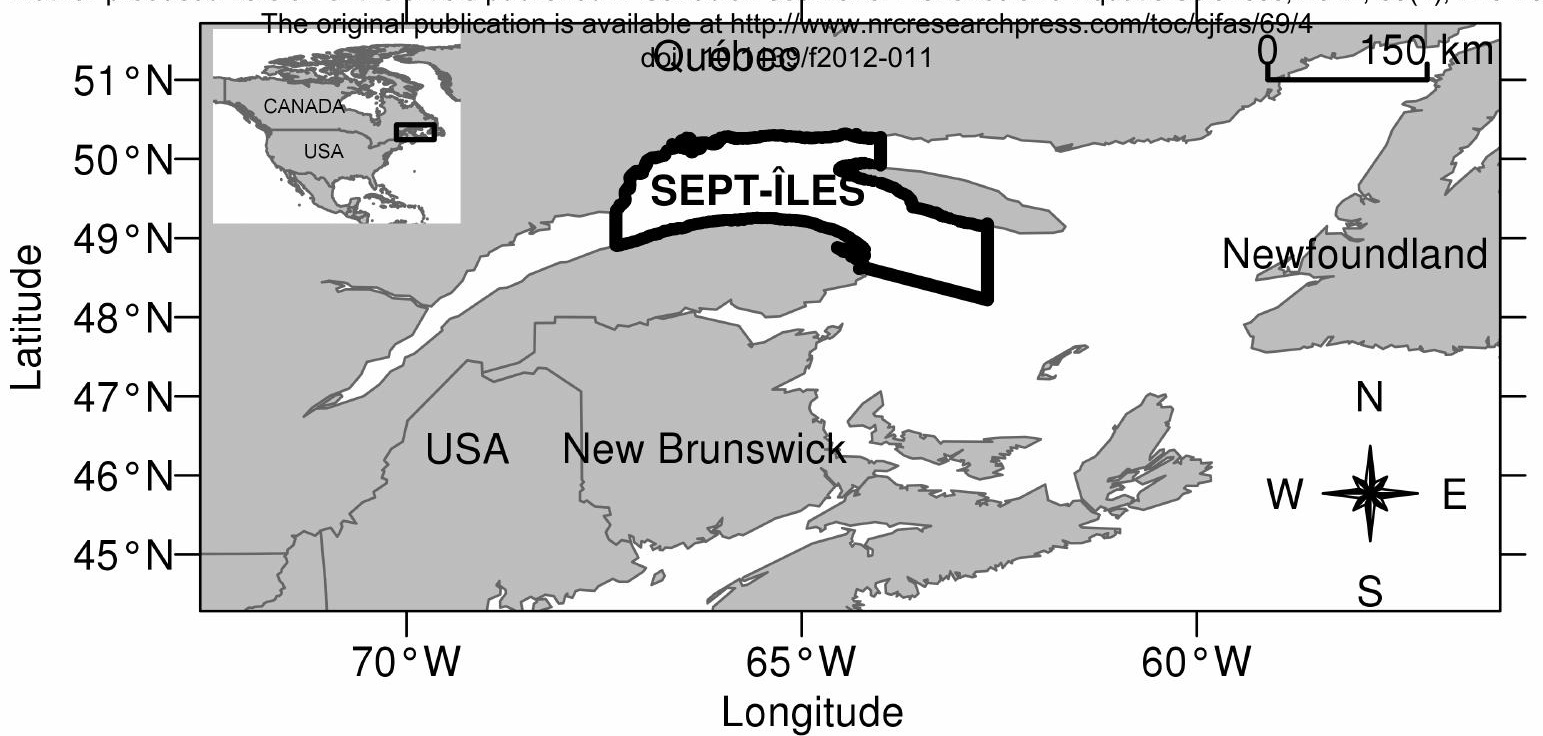




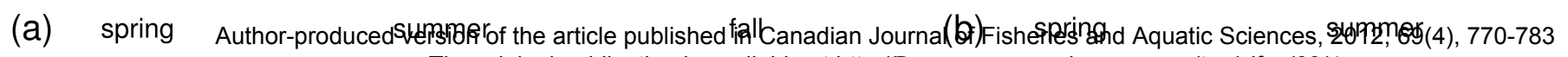
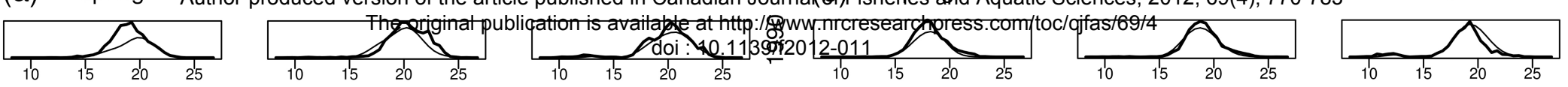

]
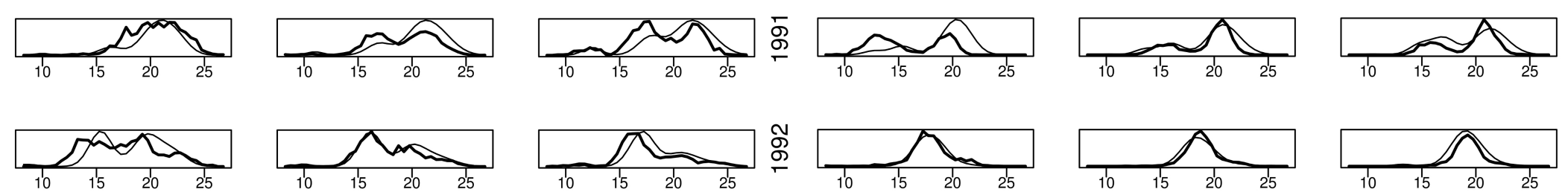

응
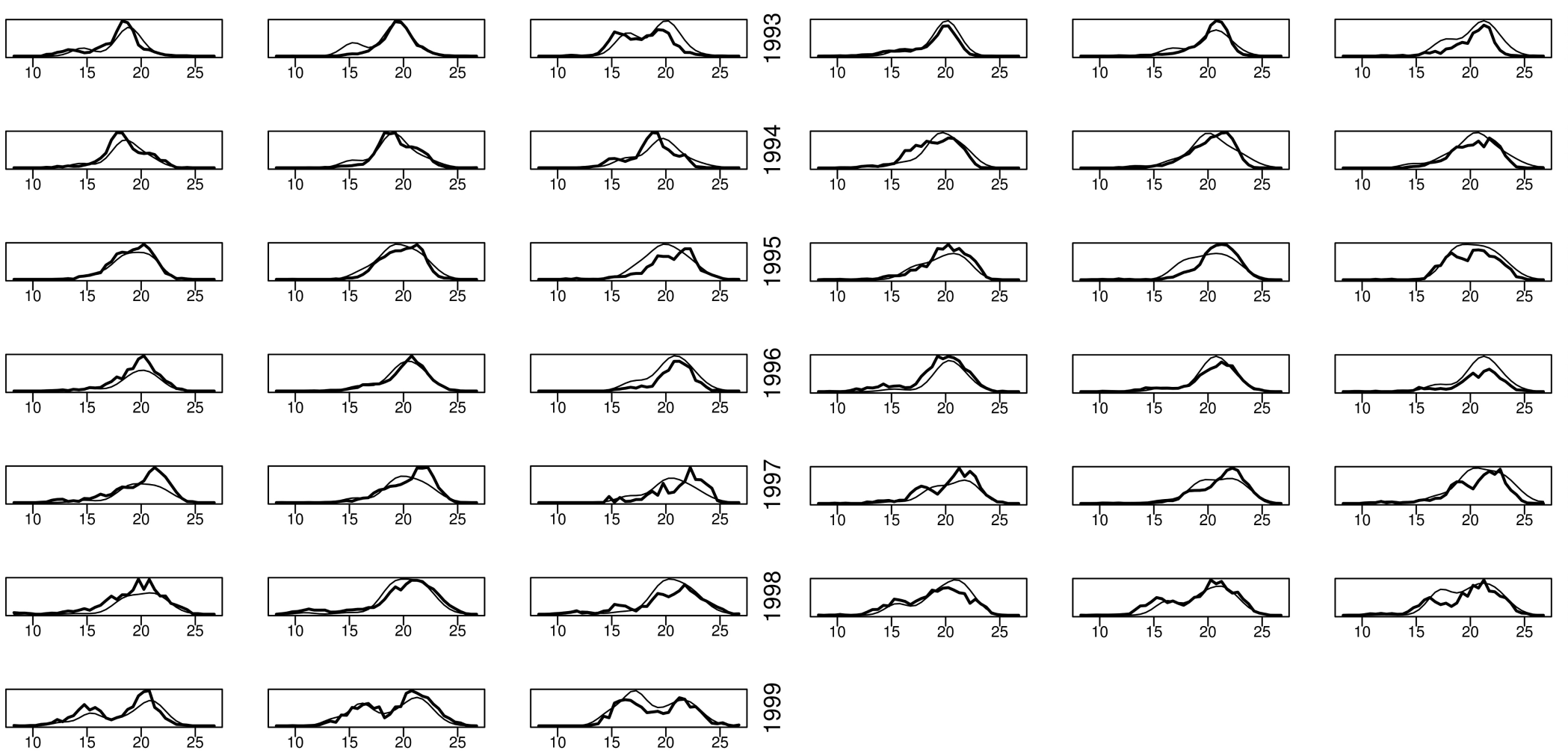

Carapace length (mm) 
Author-produced version of the article published in Canadian Journal of Fisheries and Aquatic Sciences, 2012, 69(4), 770-783

The original płlgiggtion is available at http://www.nrcresearchpress.com/togofjas/69/4
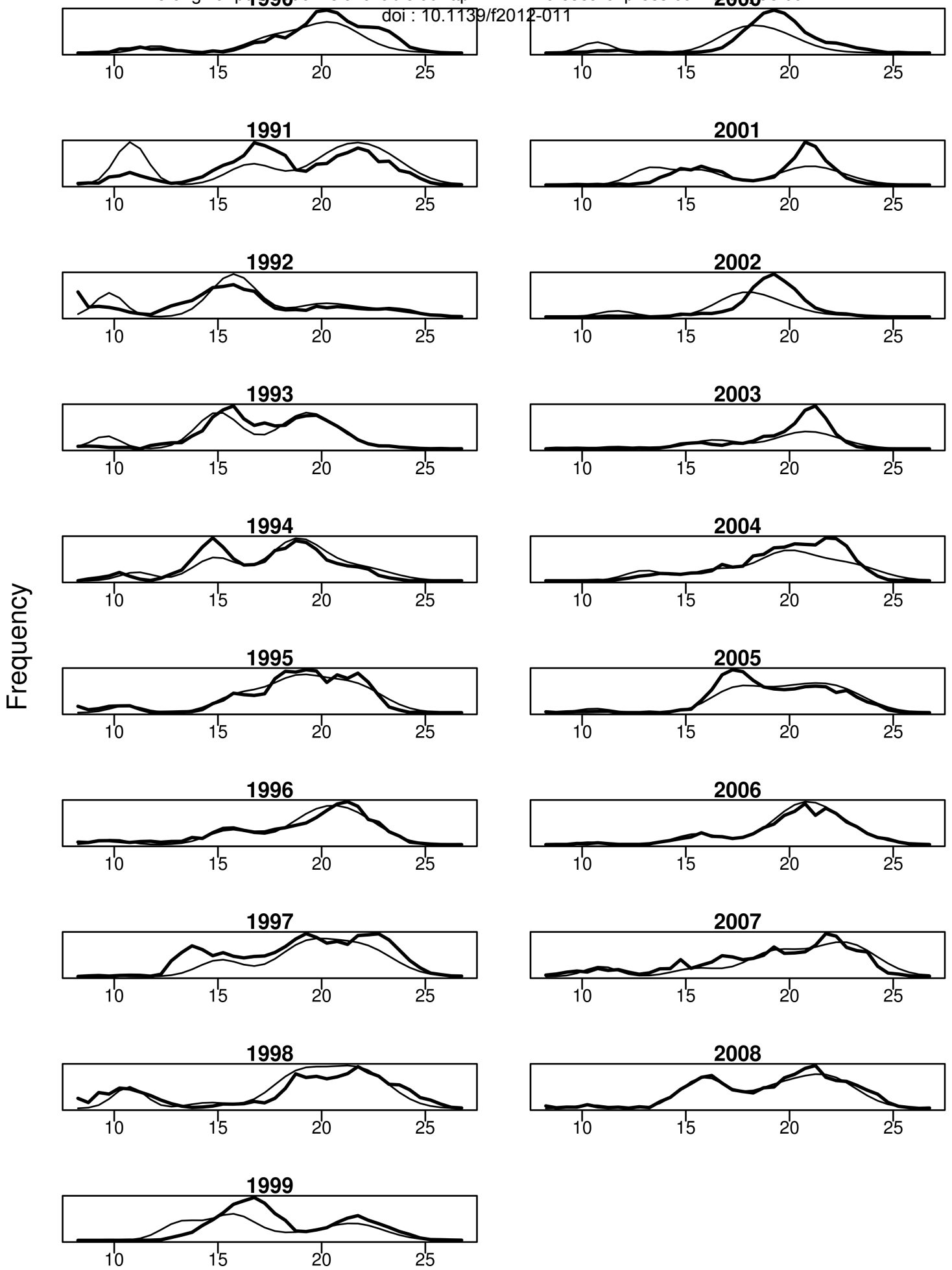

Carapace length $(\mathrm{mm})$ 


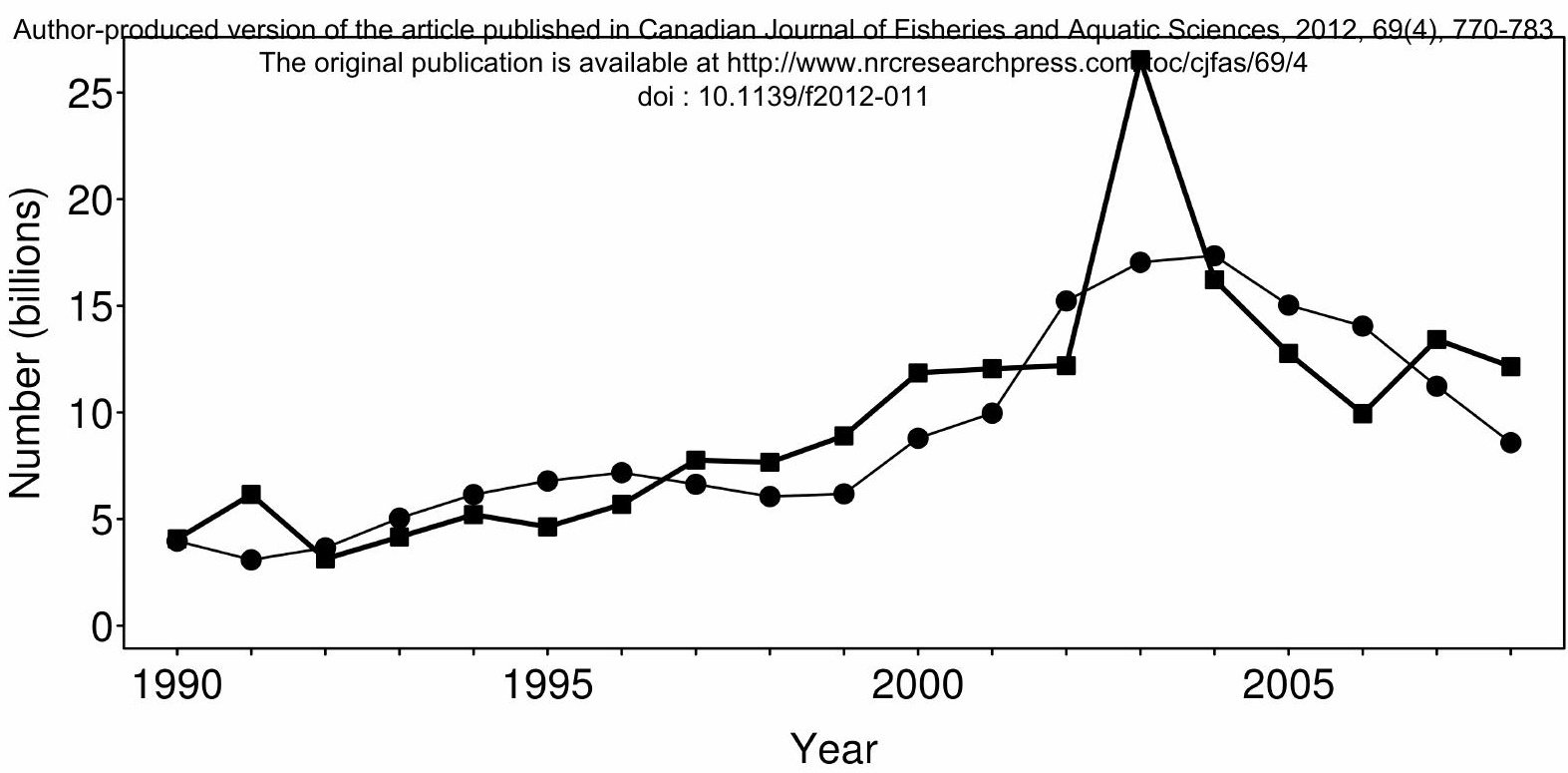




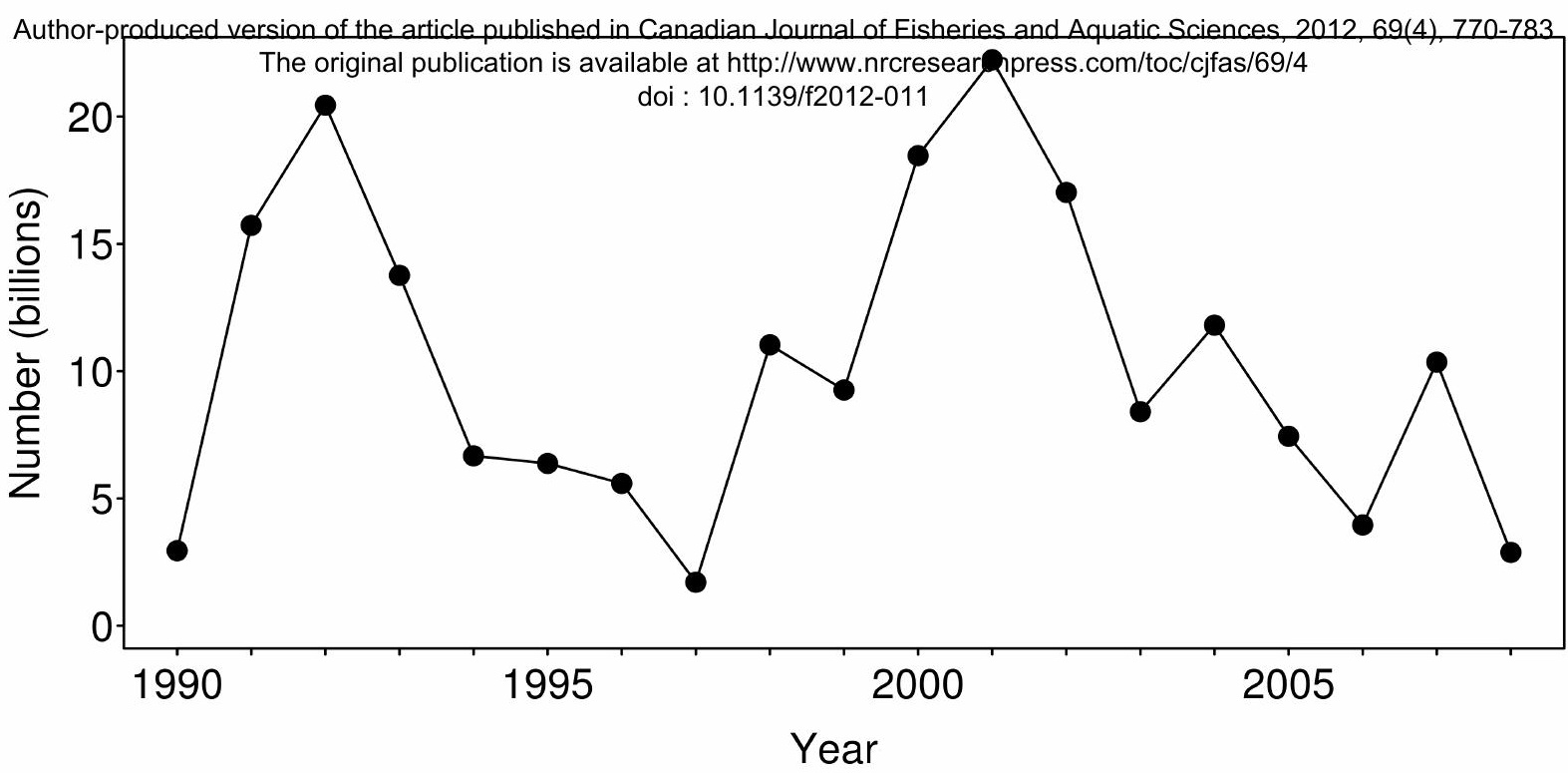


Author-produced version of the article published in Canadian Journal of Fisheries and Aquatic Sciences, 2012, 69(4), 770-783 () The original publication is available at http/ $/$ www.nrcresearchpress.com/toc/cjfas/69/4

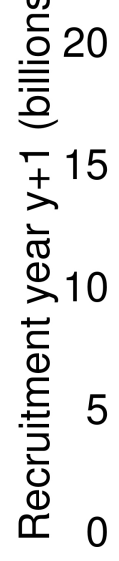
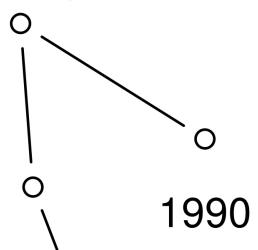

doi : $10,1139 / \mathrm{f} 2012-011$

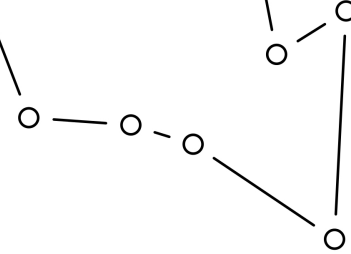

2007

2

Females year y (billions) 
(a)

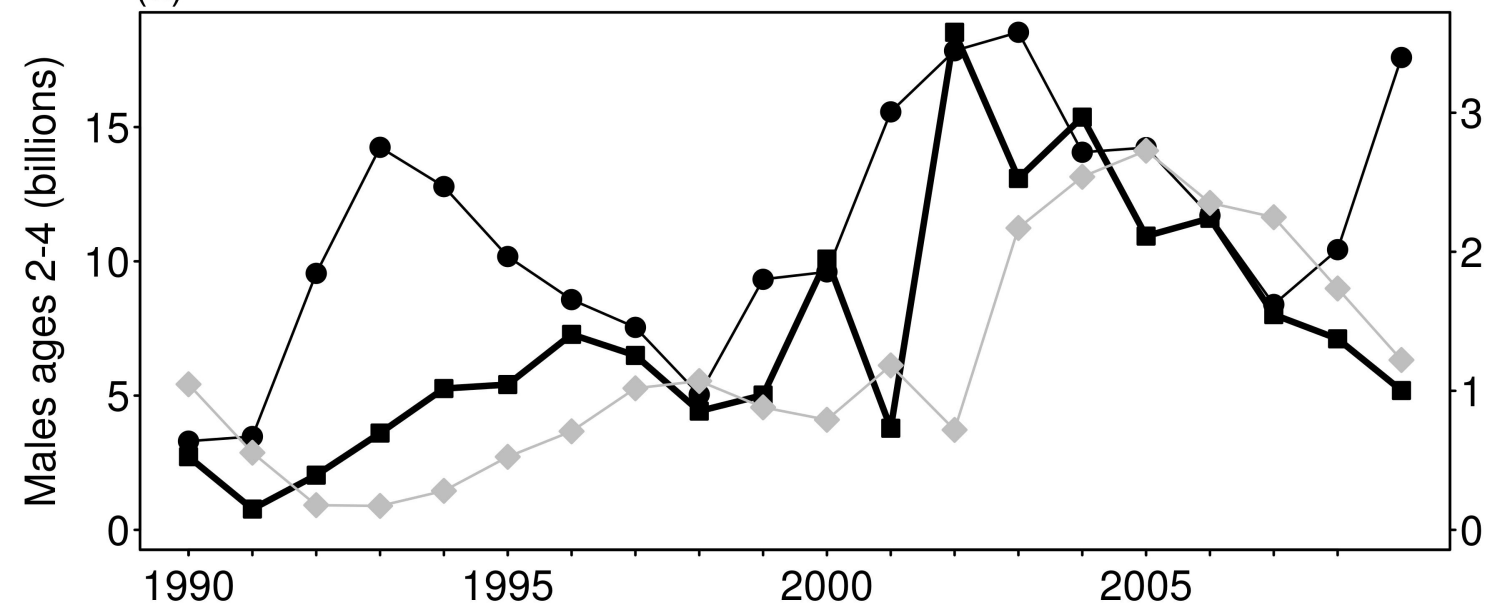

(b)

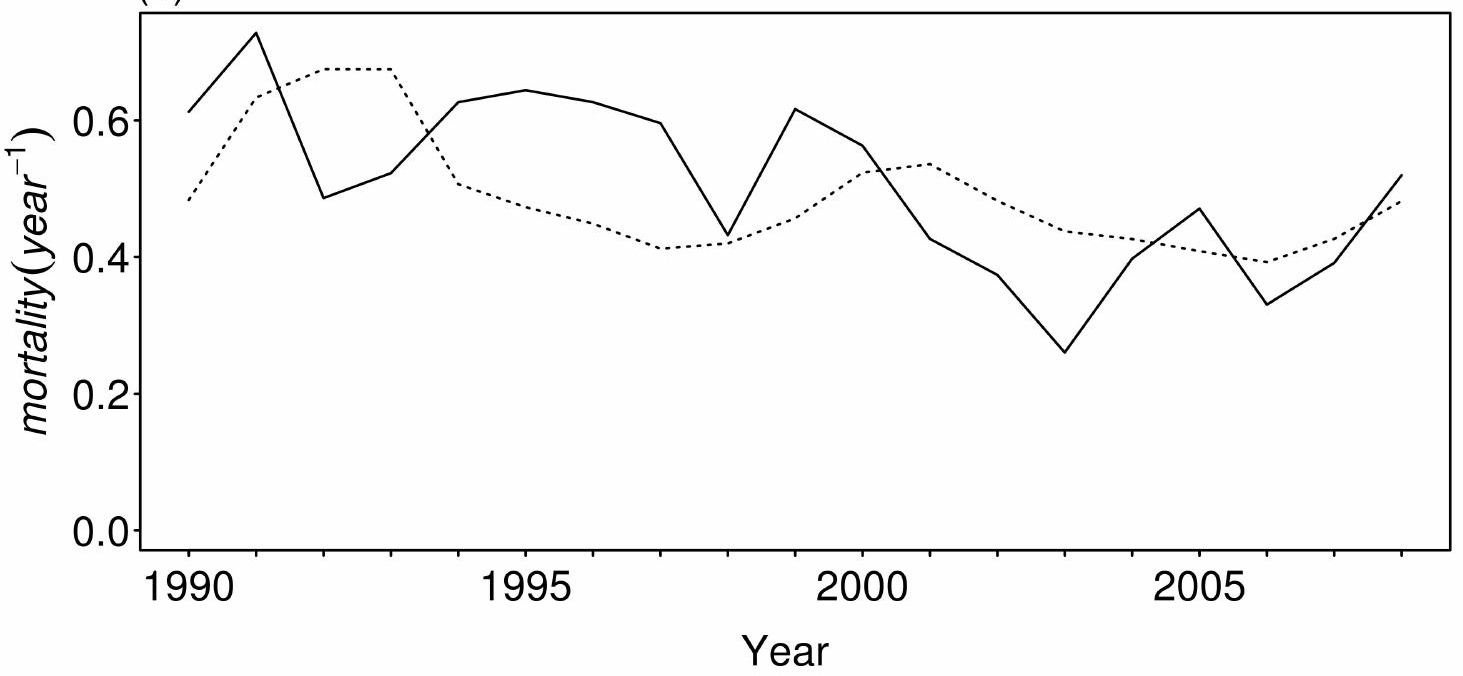


Author-produde99 96sion of the argete pubtished iagetabian Journal of Fisheries and Aquatic Sciences, 2012, 69(4), 770-783

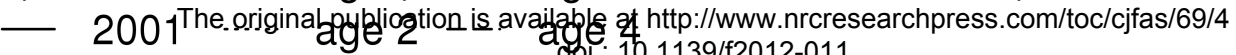
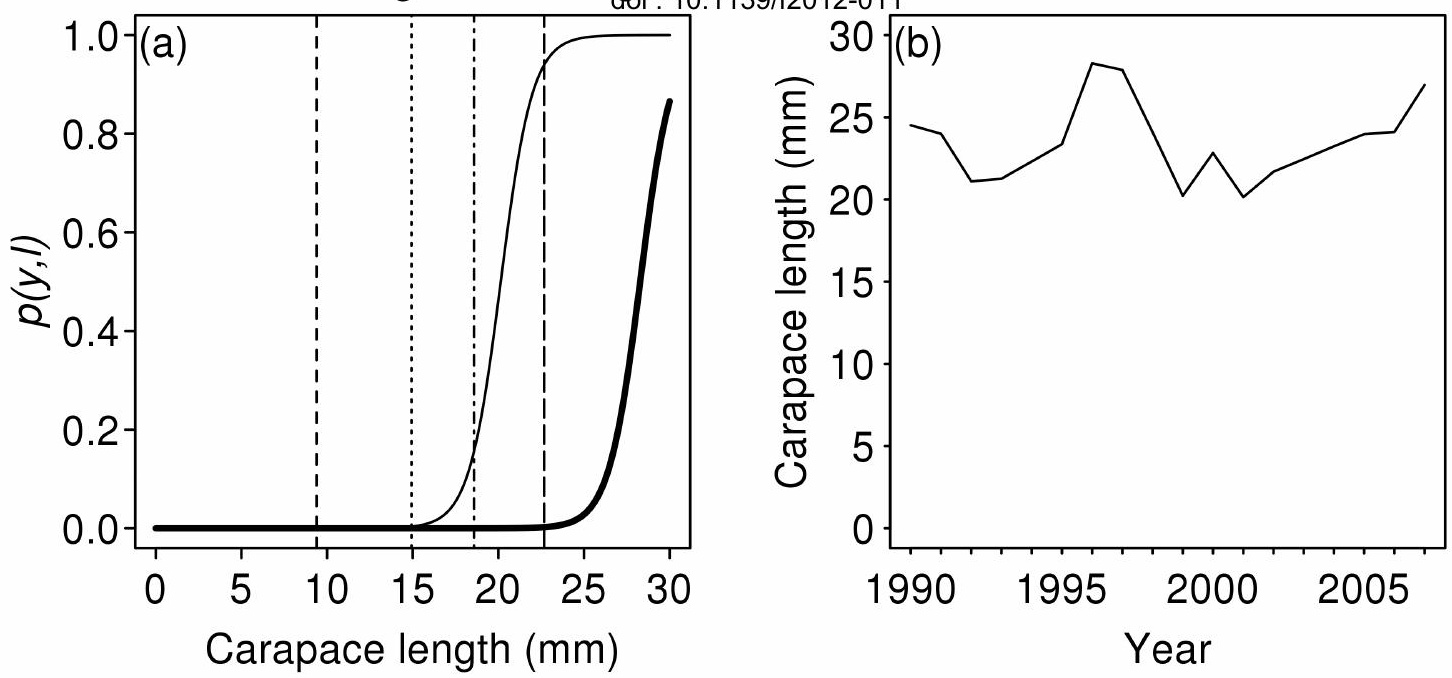